\title{
Feedback on a Sickle Cell Family Education Symposium
}

\author{
Speller-Brown $\mathrm{B}^{* 1,2}$, Robinson $\mathrm{M}^{3}$, Moffitt $\mathrm{B}^{1}$, Margulies $\mathrm{S}^{1}$ and Thaniel $\mathrm{L}^{1}$ \\ ${ }^{1}$ Children's National Hospital, Department of Hematology, Washington, DC, USA \\ ${ }^{2}$ School of Medicine and Health Sciences, George Washington University, Washington, DC, USA \\ ${ }^{3}$ University of Maryland, Maryland, USA
}

${ }^{*}$ Corresponding author: Speller-Brown B, DNP, CPNP, Children's National Hospital, Department of Hematology, George Washington University, School of Medicine and Health Sciences, Washington, DC, USA, Tel: 202-476-4747, E-mail: bsbrown@cnmc.org

Citation: Speller-Brown B, Robinson M, Moffitt B, Margulies S, Thaniel L (2020) Feedback on a Sickle Cell Family Education Symposium. J Paedatr Neonatal Dis 5(1): 101

Received Date: January 20, 2020 Accepted Date: December 02, 2020 Published Date: December 04, 2020

\begin{abstract}
Background: Sickle cell disease (SCD) is estimated to affect approximately 100,000 Americans. Children and adolescents with chronic medical conditions like SCD require comprehensive care that addresses both medical and psychosocial needs to better control their disease and ultimately maximize function at home, school and the community. The purpose of this quality improvement project was to host a symposium to provide sickle cell disease education and increase awareness of sickle cell disease to patients, families, and the surrounding community.

Methods: We hosted a 4-hour symposium to provide education to patients and families on various SCD topics. This was the $9^{\text {th }}$ annual symposium hosted by Children's National Hospital $(\mathrm{CNH})$. Lecture topics included discussions of SCD new treatments and trials, transplantation in adults and children, social and emotional management of SCD, integrative pain medicine panel and adolescent and young adult transition panel. We distributed surveys to solicit feedback from the attendees on the symposium's effectiveness and satisfaction with the topics presented.

Results: Sixty individuals attended the symposium. The majority of attendees were female (75\%). Forty- four participants completed the SCD Symposium survey. Of the attendees who completed the surveys, $70 \%$ were parents or other family member of a child with SCD, $11 \%$ health care providers, and $11 \%$ patients with sickle cell. The remaining $7 \%$ identified themselves as "other" (e.g. various sickle cell program volunteers, and industry). Only $14 \%$ of the attendees of the symposium attended last year's symposium in 2017. Participants rated the speakers of the symposium as Excellent (43\%) or Outstanding (41\%).

Conclusion: A symposium for SCD patients and families can increase knowledge of SCD. Participants were able to ask questions, interact, and learn from disease experts, as well as from each other. The symposium allowed for future implications to increase education and advocacy by evaluating parent interest in an advisory committee and/or parent support group.

Keywords: Sickle Cell; Symposium; Education; Feedback
\end{abstract}

\section{Introduction}

Sickle cell disease (SCD) is an inherited genetic disorder that affects millions of people worldwide. It is characterized by acute and chronic complications such as frequent pain crisis, acute chest syndrome, and infection that require intensive treatments. The Centers for Disease Control and Prevention estimates that SCD affects approximately 90,000 to 100, 000 Americans, affecting approximately 1 out of every 365 black or African-American births and 1 out of every 16,300 Hispanic-American births [1].

The health complications associated with SCD and frequent hospital admissions have been shown to have a negative impact on physical functioning, sleep, school performance, and overall quality of life (QoL) of patients [2]. It is known that children and adolescents with chronic medical conditions require comprehensive care that addresses both medical and psychosocial needs to better control their disease and ultimately maximize function at home, in school, and the community [3]. They are also at a greater risk for psychosocial problems, such as poor academic functioning, frequent school absences due to multiple hospital admissions, social withdrawal, and increased anxiety and depression than their healthy peers [4]. Moreover, the effects of SCD are not confined to the affected individual but also impact the entire family system including siblings and other family members [5].

Patient and caregiver education have been identified as an important part of the comprehensive care of individuals with SCD. Studies have shown that when caregivers have a greater understanding of a child's disease there are more positive disease outcomes 
and improved disease management in children [5,6]. Furthermore, enhanced parental knowledge about SCD has been associated with increased treatment adherence, reduced complications, and alleviation of fears associated with diagnosis [7]. Results of a study by Smith and Brownell [8] supported the need for improved education and awareness for at risk groups like SCD. Educational programs allow a unique opportunity for patients, families, and providers to step away from the healthcare environment and allow the opportunity to enhance interactions and consequently improve their understanding of SCD, as well as, promote better health outcomes and quality of care [9]. One study that examined an interactive health education program suggests that given the role of parents in guiding or overseeing their child's healthcare, disease-related knowledge and coping may optimally need to occur within a family context [10]. In addition, research also reveals that education interventions that address health beliefs and include a behavioral component are more likely to increase medication adherence in the pediatric sickle cell disease population [11]. Furthermore, parents and caregivers who did not receive adequate disease education have shown to acquire information online rather than through their physician [7]. Patient and caregiver education have been identified as an important part of the comprehensive care of individuals with SCD. It is reasonable to hypothesize that as a child and caregiver becomes more aware and knowledgeable of SCD management, they feel a greater sense of empowerment and control. A study by Sahar Abd El-Gawad [12] showed that feeling empowered enabled parents to more effectively manage their child's illness, develop coping skills, and may lead to high quality care and that increased education empowered mothers to be more knowledgeable and act effectively.

With the high prevalence of such a serious condition as SCD, prevention, education, and management are important factors to consider. Providing opportunities for education is an important endeavor. A study by Thompson et al. [13], showed that symposium styled presentations were a good way to impart information and was well received by families who reported that they not only benefited from listening to didactic lectures from experts, but also from talking to other families who have children with SCD. The goal of this report was to examine the impact of the $\mathrm{CNH}$ symposium and assess what education topics families deemed as important and to equip patients and families with knowledge of SCD.

\section{Symposium Design and Methods}

The Institutional Review Board at $\mathrm{CNH}$ approved this quality improvement project (Protocol No. 11531). In order to provide education and increase awareness of SCD to patients, families, and the surrounding community, the Hematology division at $\mathrm{CNH}$ hosts an annual Sickle Cell Family Education Symposium. It is held in the auditorium at CNH's main campus. The Sickle Cell Program treats approximately 1,400 patients and is considered one of the largest centers for SCD in the country. Patients and families reside primarily in the District of Columbia (DC), Maryland and Virginia. Patients and families were invited to this $9^{\text {th }}$ annual symposium three months prior to the event. It was advertised by distribution of flyers in the SCD clinic when families attended clinic appointments and electronic invitations were sent via email. This symposium was a 4-hour event held in November 2018, and included lectures and expert panels by sickle cell providers and provided education on various SCD topics. So as to make it convenient for families, the symposium was held in the auditorium, on a Saturday, was free of charge, breakfast was provided free of charge and parking was paid. The symposium was funded by a grant from The Children's Health Board at CNHS.

The Symposium began with a keynote address from the Division Chief of the hematology department. Topics covered included Transplantation in Adults, Transplantation in Children, New Treatments and Trials, Integrative Medicine, Transitioning from Pediatric to Adult Care and Social and Emotional Management of SCD. Transplantation was addressed as a curative therapy in SCD, which has been done for over 30 years but is still vastly underutilized. Families were informed on how to pursue HLA (human leukocyte antigen) typing for patients with SCD. HLA type is like a blood type for the immune system. Bone marrow transplant works best if a donor is a HLA-match. New Treatments and Trials were presented by the director of SCD. The content included new drug therapies and eligibility criteria. The Integrative Medicine component and panel addressed non-opioid methods of managing sickle cell pain, including a demonstration of acupuncture. The transition component included a short presentation on transitioning care, followed by a panel of adult hematology providers, a patient who had transitioned to adult care and his parent and a SCD pediatric social worker, nurse coordinator and pediatric nurse practitioner. The symposium allowed patients and families with SCD to ask questions, interact, and learn from disease experts as well as from each other.

\section{Results}

A total of 60 SCD symposium attendees signed the registry. The majority of the attendees were female (75\%). Forty- four participants completed the SCD Symposium Evaluation. Of the attendees who completed the surveys, 70\% (31) were parents or other family members of a child with SCD, 11\% (5) health care providers, and 11\% (5) patients with sickle cell. The remaining $8 \%$ (3) identified themselves as "other" (e.g. various sickle cell program volunteers, and industry). The number of attendees under the age of 18 was unknown because they were not asked to sign the symposium registry. Participants were asked if they had attended last year's symposium in 2017 and 14\% (6) responded yes. They were also asked to rate the speakers of the symposium as Excellent (43\%) or Outstanding (41\%). Only 9\% ranked the speakers as good and 7\% did not answer the question. The participants were asked to rank the helpfulness of the topics discussed at the symposium from 1-6 (1 being most helpful) (Table 1). Unfortunately only 18 of the 44 participants completed this section correctly (some listed all topics as most helpful (1) or some did not rank all topics). If the participant did not answer the question correctly, their response was removed from the analysis. It was determined that the 18 participants who completed this section correctly, sufficiently represented the symposium participants. 


\begin{tabular}{|c|c|c|}
\hline Education Topics & $\left(\mathbf{N}={ }^{*} \mathbf{1 8}\right)$ & $\begin{array}{c}\text { Percentage (\%) that rated } \\
\text { topics most helpful }\end{array}$ \\
\hline $\begin{array}{c}\text { Transplantation in } \\
\text { Children }\end{array}$ & 7 & 38.89 \\
\hline $\begin{array}{c}\text { New Treatments and } \\
\text { Trials }\end{array}$ & 4 & 22.22 \\
\hline $\begin{array}{c}\text { Integrative Medicine } \\
\text { Transition Panel }\end{array}$ & 3 & 22.22 \\
\hline $\begin{array}{c}\text { Social and Emotional } \\
\text { Management }\end{array}$ & 0 & 16.67 \\
\hline Transplant in Adults & 0 & 0.00 \\
\hline
\end{tabular}

*Participants were asked to rank the helpfulness of different topics presented at the symposium between 1-6 (1 being most helpful). $\mathrm{N}=$ number of participants that rated the topic as 1 (most helpful). Of the 44 surveys completed, only eighteen participants completed this section correctly and ranked each speaker

Table 1: Education Topics Rated Most Helpful

Transplantation in Children was rated as the most helpful of the topics (39\%), Integrative Medicine and New Treatment and Trials (22\%) were found to be equally helpful. The Transition panel was ranked as least helpful (17\%). Overall, out of the 18 attendees who completed this section, no one ranked Social and Emotional Management and or Transplant in Adults as helpful. Participants were also asked if there were other topics they would have liked to have been presented and general comments or suggestions about how we could improve future SCD symposiums (Table 2). Topics included gene editing to complement gene therapy and parent and child/ youth support groups. Some felt the symposium was rushed and would extend it by a couple of hours to allow more time for questions. Others would prefer that more layman's terms were used in lectures and would like to obtain presenters contact information. Other topics they wished were included were home pain treatment methods and information on medical marijuana. One parent identified as being a new parent of a child with SCD, wanted more information on how to improve her child's quality of life in the years to come. Another participant thought that having more patients talk about their everyday living with SCD and more information on integrative medicine would have been helpful.

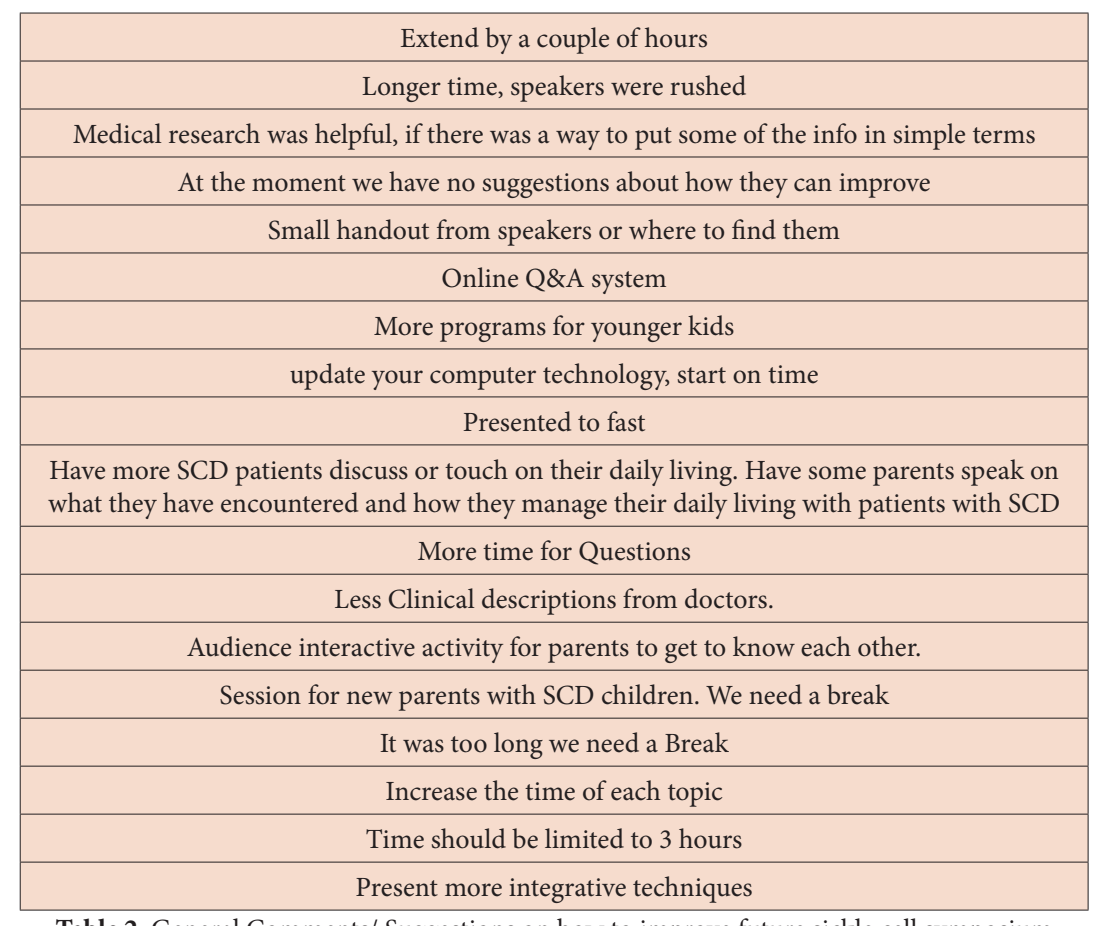

The overall rating of the symposium was outstanding and excellent. Of those who responded, $82 \%$ indicated that they would attend another symposium. Most participants (68\%) were interested in organizing and participating in a sickle cell parent support group at $\mathrm{CNH}$ and $66 \%$ indicated that they would be interested in participating in a sickle cell parent advisory board.

\section{Discussion}

The primary goals of this quality improvement project were to examine the impact of the symposium, assess what education topics families deemed most important, and to equip patients and families with knowledge of SCD. Overall, the symposium was 
well received by most participants. The symposium was rated as outstanding and excellent. Eighty-two percent $(\mathrm{N}=36)$ indicated that they would attend another symposium about SCD. We think this indication increased because the topics this year were more appealing to parents of infants with SCD and individuals who wanted more information about pain management and curative therapies. Of those who completed the survey, 38.9\% (7) rated the session about Transplantation in Children as most helpful. In recent years, interest in stem cell transplant has increased among patients with SCD and their families. Two studies conducted by Roth et al. [14], and Thompson et al. [13], showed that a majority of patients with SCD and their families were interested in stem cell transplant and were willing to accept the risk of acute mortality in hopes of achieving a cure. Other studies have reported similar results. Similarly, $22 \%$ of participants rated New Treatments and Trials and Integrative Medicine (alternatives to opioid treatment) as most helpful. However, participants rated the transition panel as least helpful and did not rate Social and Emotional Management of SCD. These results suggest that participants who attended the symposium were more interested in hearing about clinical and research advances in the treatment of SCD than psychosocial issues. It can also be inferred that most of the families who attended the symposium had young children and were less interested in hearing about adolescent transition.

In addition, the results also reflect increasing popularity and acceptance among sickle cell patients and health care providers in alternative treatments as an effective treatment modality for sickle cell pain. In a study conducted by Thompson \& Eriator [15], they found that $91.6 \%$ of patients with SCD used complementary alternative medicine (CAM). Forty-two percent used prayer and spiritual and energy healing, $28 \%$ used relaxation techniques, exercise, imagery, and diet, $12 \%$ used herbal medicines, and $5 \%$ massage [16].

\section{Conclusion}

This quality improvement project had several limitations. First, the sample size was small and may not be representative of all patients with SCD and their families. In addition, it can be inferred that patients and families who attended the symposium were more motivated and interested in learning about sickle cell disease than most of our patients and families. As a result, it is unclear if these findings can be generalizable to the patient population at Children's National. Lastly, future surveys should include questions assessing SCD knowledge in order to assess the efficacy of the symposium as an educational intervention. It should also include questions about income and education in order to assess what effect these variables have on attendance and who really benefits from the symposium. This knowledge could help in the development of future symposiums. Despite these limitations, findings from this quality improvement project showed that the symposium is an effective tool for disseminating information about clinical care and research trials to patients, families and healthcare providers and that most participants deemed the topics as helpful and informative. It was also helpful in developing a SCD parent advisory council and parent support group.

\section{Acknowledgement}

The symposium was funded by The Children's Health Board at Children's National Hospital. The authors thank all the presenters for sharing their SCD expertise and the patients and families who attended the symposium and participated in the surveys.

\section{Declaration of Conflicting Interests}

The authors(s) declare no potential conflicts of interest with respect to the research, authorship and /or publications of this article.

\section{References}

1. Centers for Disease Control and Prevention (2017) Data \& statistics on sickle cell disease, USA.

2. Madani BM, Al Raddadi R, Al Jaouni S, Omer M, Al Awa MI (2018) Quality of life among caregivers of sickle cell disease patients: a cross sectional study. Health Qual Life Outcomes 16: 176.

3. Fields ME, Hoyt-Drazen C, Abel,R, Rodeghier MJ, Yarboi JM, et al. (2016) A pilot study of parent education intervention improves early childhood development among toddlers with sickle cell disease. Pediatr Blood Cancer 63: 2131-8.

4. Crosby, LE, Joffe, NE, Irwin MK, Strong H, Peugh J, et al. (2015) School performance and disease interference in adolescents with sickle cell disease. Phys Disabil 34: $14-30$

5. Jenerette CM, Brewer C (2010) Health-related stigma in young adults with sickle cell disease. J Natl Med Assoc 102: 1050-5.

6. Asnani MR, Quimby KR, Bennett QR, Francis DK (2016) Interventions for patients and caregivers to improve knowledge of sickle cell disease and recognition of its related complications. Cochrane Database Syst Rev 10: CD011175.

7. Lebensburger JD, Grosse SD, Altice JL, Thierry JM, Ivankova NV (2015) Understanding and improving health education among first-time parents of infants with sickle cell anemia in Alabama: a mixed methods approach. J Pediatr Hematol Oncol 37: 35-42.

8. Smith M, Brownell G (2018) Knowledge, beliefs, attitudes, and behaviors regarding sickle cell disease: Implications for prevention. Soc Work Public Health 33: 299-316.

9. Smith M, Praetorius RT (2015) The Challenges and Opportunities Associated with Sickle Cell Disease Prevention, Education, and Management. Soc Work Public Health 30: 592-612.

10. Hazzard A, Celano M, Collins M, Markov Y (2010) Effects of starbright world on knowledge, social support, and coping in hospitalized children with sickle cell disease and asthma. Children's Health Care 31: 69-86.

11. Walsh KE, Cutrona SL, Kavanagh PL, Crosby LE, Malone C, et al. (2014) Medication adherence among pediatric patients with sickle cell disease: a systematic review. Pediatrics 134: 1175-83. 
12. Sahar Mahmoud El-Khedr Abd El-Gawad (2017) Empowering mothers to overcome sickle cell crisis in their children through engagement and education. Am J Nurs Res 5: 182-90.

13. Thompson AL, Bridley A, Twohy E, Dioguardi J, Sande, J, et al. (2013) An educational symposium for patients with sickle cell disease and their families: Results from surveys of knowledge and factors influencing decision s about hematopoietic stem cell transplant. Pediatric Blood Cancer 60:1946-51.

14. Roth M, Krystal J, Manwani D, Driscoll C, Ricafort R (2012) Stem cell transplant for children with sickle cell anemia: parent and patient interest. Biol Blood Marrow Transplant 18: 1709-15.

15. Thompson WE, Eriator I (2014) Pain control in sickle cell disease patients: Use of complementary and alternative medicine. Pain Med 15: 241-6.

16. Majumdar S, Thompson W, Ahmad N, Gordon C, Addison C (2013) The use and effectiveness of complementary alternative medicine for pain in sickle cell anemia. Complement Ther Clin Pract 19: 184-7. 